\title{
Changes to Fetal Steroidogenesis Caused by Maternal Smoking
}

\author{
K. ADAMCOVÁ ${ }^{1}$, L. KOLÁTOROVÁ ${ }^{2}$, T. CHLUPÁČOVÁ ${ }^{2}$, M. ŠIMKOVÁ \\ H. JANDÍKOVÁ ${ }^{2}$, A. PAŘÍZEK ${ }^{1}$, L. STÁRKA ${ }^{2}$, M. DUŠKOVÁ ${ }^{2}$
}

${ }^{1}$ Department of Obstetrics and Gynecology of the First Faculty of Medicine and General Teaching Hospital, Prague, Czech Republic, ${ }^{2}$ Institute of Endocrinology, Prague, Czech Republic

Received May 30, 2017

Accepted June 23, 2017

\section{Summary}

Smoking during pregnancy presents health risks for both the mother and her child. In this study we followed changes in the production of steroid hormones in pregnant smokers. We focused on changes in steroidogenesis in the blood of mothers in their $37^{\text {th }}$ week of pregnancy and in mixed cord blood from their newborns. The study included 88 healthy women with physiological pregnancies (17 active smokers and 71 nonsmokers). We separately analyzed hormonal changes associated with smoking according to the sex of newborns. In women with male fetuses, we found higher levels of serum cortisone, dehydroepiandrosterone (DHEA), 7a-OH-DHEA, 17-OH pregnenolone, testosterone, and androstenedione in smokers at the $37^{\text {th }}$ week compared to non-smokers. In women with female fetuses, we found lower serum levels of $7 \beta-\mathrm{OH}-\mathrm{DHEA}$ and higher androstenedione in smokers at the $37^{\text {th }}$ week. We found significantly higher levels of testosterone in newborn males of smokers and higher levels of 7a-OH-DHEA in female newborns of smokers. Smoking during pregnancy induces changes in the production of steroids in both the mother and her child. These changes are different for different fetal sexes, with more pronounced changes in mothers carrying male newborns as well as in the newborn males themselves.

\section{Key words}

Smoking in pregnancy • Newborn • Delivery • Androstenedione • Testosterone $\bullet$ Dehydroepiandrosterone metabolites

\section{Corresponding author}

M. Dušková, Institute of Endocrinology, Národní 8, 11694 Prague 1, Czech Republic. E-mail: mduskova@endo.cz

\section{Introduction}

Smoking during pregnancy endangers the health of the mother as well as the organism of the developing child. Smoking by women during pregnancy is a serious risk factor for a wide range of developmental health complications. In 2012, an analysis of data from 2000-2009 from the National Register of Mothers at Childbirth and the National Register of Newborns from the Institute of Health Information and Statistics of the Czech Republic was published. This analysis was focused on the use of alcohol, tobacco and illegal drugs in women who were hospitalized due to complications related to birth or in the newborn child. During that period 60,502 women were registered smokers from a total of $1,008,821$ mothers. This means that about $6.5 \%$ of women admitted to smoking at the end of pregnancy (Nechanská et al. 2012). This data is likely to be markedly influenced by the fact that many women did not admit to smoking during pregnancy.

According to longitudinal studies, the consequences of smoking during pregnancy include the risk of premature labor being increased by $23 \%$, and medically indicated prematurely induced labor increased by $28 \%$. Medically indicated prematurely induced labor has been associated with the non-desirable side-effects of smoking during pregnancy (Montgomery and Ekbom 2002). Children of smokers have more frequent congenital developmental disorders. Increased risks of malformed extremities, congenital heart defects, malformations of the urogenital system, and cleft lips and palates have also been reported. Newborns of mothers who smoked during pregnancy have on average lower 
birth weights than newborns of non-smokers, with a direct relationship to the number of cigarettes smoked (Cressman et al. 2012).

Smoking during pregnancy significantly influences the production of many fetal hormones. Studies have described a higher production of ACTH and cortisol, with cortisol levels in children of smoking mothers positively correlated with the number of cigarettes smoked (Vavrarigou et al. 2006). Children of smokers have a lowered catecholamine reaction to hypoxia and stress during birth. This decreased reactivity of the adrenergic system could be related to the increase of Sudden Infant Death Syndrome (SIDS) in children of smoking mothers (Divers et al. 1981). There is a 2.5-3 times higher risk of SIDS in children of smokers than in children of women who did not smoke during pregnancy (Somm et al. 2008).

Children that have been exposed to smoking during prenatal development have more frequent cognitive function defects, behavioral disorders, attention problems, hyperactivity, psychological problems, and a higher tendency to become addicted. These disorders can last until puberty, adolescence, and even young adulthood. Epidemiological studies have shown that the higher incidence of these disorders in such prenatally exposed children and adults persist even after controlling for interfering factors. In addition, there are also direct correlations to the number of cigarettes smoked (Kukla et al. 2008). It has been shown that expectant mothers who smoke during pregnancy have not just more frequent effects on the fetus/child, but also various later effects that may be manifested in adulthood as a result of defective fetal programming of the exposed individual (Dušková et al. 2014). In particular, the production of steroid hormones, which have both genomic and neuroactive activity, may be one of the links between the effects of smoking during pregnancy and the later effects on the child as part of a wide spectrum of behavioral problems.

In physiological pregnancies, there are differences in the levels of steroid hormones in the pregnant woman depending on the sex of the fetus, and there are differences in the steroids of newborns depending on its sex, though the data from the literature are not consistent (Kuijper et al. 2013). At the same time, changes in the production of steroid hormones induced by smoking are different for women and men (Dušková et al. 2012, Jandíková et al. 2015, Jandíková et al. 2017), and this has been demonstrated in experimental models of prenatal nicotine exposure (Cross et al. 2016). This highlights the necessity for analyzing changes in smoking women during pregnancy separately depending on the sex of her child. The aim of this study was to follow changes in the production of steroid hormones caused by smoking during pregnancy. We focused on changes in steroidogenesis in the blood of mothers in the $37^{\text {th }}$ week of pregnancy and in mixed cord blood from the newborn.

\section{Methods}

Our study included a total of 88 healthy pregnant women with a physiological course of gravidity, of which 17 were active smokers and 71 non-smokers. All women were of Czech nationality and gave birth spontaneously. Ex-smokers and passive smokers were excluded from the study. Other exclusion criteria were another addiction in their history, the use of medicines affecting steroidogenesis, gestational diabetes, hypertension, thyropathy, complications of pregnancy (hyperemesis, bleeding, uterine inflammation, or the risk of premature birth), intrauterine growth restriction, and cesarean section. Only singleton pregnancies were included. All participants signed informed consent and were informed about the study aims. The study was approved by the Ethical Commission of the General Faculty Hospital (protocol number 114/15).

Women were examined during the $37^{\text {th }}$ week of pregnancy, when they filled out an anonymous standardized questionnaire on their age, height, weight, gravidity/parity, complications during pregnancy, socioeconomic status, smoking history, knowledge on the dangers of smoking during pregnancy, and addiction to nicotine. The sex of the child was noted at birth.

Samples of venous blood from the mothers were taken from the cubital vein between 8:00 and 10:00 o'clock, during the $37^{\text {th }}$ week of pregnancy. At birth, a sample of mixed cord blood was taken. Blood samples were taken into Vacuette tubes (plastic tubes for sampling coagulating blood with a coagulation activator and separation gel). Serum was obtained by centrifugation for 5 min at $2000 \mathrm{~g}$ at $4{ }^{\circ} \mathrm{C}$, and then stored at $-20^{\circ} \mathrm{C}$.

Selected steroid hormones (cortisol, cortisone, dehydroepiandrosterone (DHEA), $7 \alpha$-hydroxy-dehydroepiandrosterone ( $7 \alpha-\mathrm{OH}-\mathrm{DHEA}), 7 \beta$-hydroxy-dehydroepiandrosterone (7 $\beta$-OH-DHEA), 7-oxo-dehydroepiandrosterone (7-oxo-DHEA), pregnenolone, 
$17 \alpha$-hydroxy-pregnenolone (17-OH-pregnenolone), testosterone, androstenedione, progesterone, 17-OHprogesterone, corticosterone, estrone (E1), estradiol (E2), and estriol (E3)) were measured by LC-MS/MS using methods described elsewhere (Sosvorová et al. 2015a,b, Vítků et al. 2015, Vítků et al. 2016).

\section{Statistical analysis}

Data were transformed by Box-Cox transformation before further processing due to the nonGaussian distribution and non-constant variance (heteroscedasticity) of all variables. Subsequently, Student's t-test was used for comparison of steroid levels between smokers and non-smokers. The statistical software Statgraphics Centurion, version XVI from Statpoint Inc. (Warrenton, VA, USA) was used for all data transformations and ANOVA analyses.

\section{Results}

As shown in Table 1, smokers and non-smokers did not differ in age. Smokers had a higher weight gain during pregnancy of an average of $4 \mathrm{~kg}$. In contrast, the birth weights of the children of smokers were lower by an average of $300 \mathrm{~g}$. The women were divided according to the sex of the newborn child, and hormonal changes in relationship to smoking were analyzed separately.

Table 1. Characteristics of the study participants.

\begin{tabular}{|c|c|c|c|c|c|c|c|}
\hline & Number & $\begin{array}{l}\text { Age of the } \\
\text { mother } \\
\text { (years) }\end{array}$ & $\begin{array}{c}\text { Maternal } \\
\text { weight gain } \\
\text { (kg) }\end{array}$ & $\begin{array}{l}\text { Birth weight } \\
\text { of the child } \\
\text { (g) }\end{array}$ & $\begin{array}{c}\text { Daily cigarettes } \\
\text { smoked before } \\
\text { pregnancy } \\
\text { (n) }\end{array}$ & $\begin{array}{l}\text { Daily cigarettes } \\
\text { smoked during } \\
\text { pregnancy } \\
\text { (n) }\end{array}$ & $\begin{array}{c}\text { Length of } \\
\text { smoking } \\
\text { (years) }\end{array}$ \\
\hline $\begin{array}{l}\text { Non-smokers, } \\
\text { male child }\end{array}$ & 34 & $32.25 \pm 4.95$ & $14.71 \pm 4.90$ & $3587.50 \pm 465.70$ & 0 & 0 & 0 \\
\hline $\begin{array}{l}\text { Non-smokers, } \\
\text { female child }\end{array}$ & 37 & $31.22 \pm 3.16$ & $14.00 \pm 3.71$ & $3348.33 \pm 322.04$ & 0 & 0 & 0 \\
\hline $\begin{array}{l}\text { Smokers, } \\
\text { male child }\end{array}$ & 8 & $29.25 \pm 3.70$ & $18.88 \pm 4.59$ & $3286.25 \pm 433.60$ & $17.14 \pm 7.95$ & $6.14 \pm 2.53$ & $10.00 \pm 2.88$ \\
\hline $\begin{array}{l}\text { Smokers, } \\
\text { female child }\end{array}$ & 9 & $31.55 \pm 4.14$ & $18.11 \pm 5.80$ & $3104.44 \pm 396.71$ & $25.88 \pm 16.67$ & $6.11 \pm 5.42$ & $14.25 \pm 5.61$ \\
\hline
\end{tabular}

Data are means $\pm \mathrm{SD}$.

In the group of women who were carrying a male fetus, the women who smoked had significantly higher levels of cortisone, DHEA, $7 \alpha-\mathrm{OH}-\mathrm{DHEA}$, 17-OH-pregnenolone, testosterone and androstenedione at the $37^{\text {th }}$ week. Other measured steroids (cortisol, 7 $\beta$-OH-DHEA, 7-oxo-DHEA, pregnenolone, progesterone, 17-OH-progesterone, corticosterone, E1, E2, E3) did not differ between smokers and non-smokers (Fig. 1).

In the group of women who were carrying a female fetus, the women who smoked had significantly lower levels of 7 $\beta-\mathrm{OH}-\mathrm{DHEA}$ and higher levels of androstenedione at the $37^{\text {th }}$ week. In addition, smokers had borderline lower levels of E3, though not statistically significant. Other measured steroids (cortisol, cortisone,
DHEA, 7 $\beta$-OH-DHEA, 7-oxo-DHEA, pregnenolone, 17-OH-progesterone, testosterone, progesterone, 17-OHprogesterone, corticosterone, E1, E2) did not differ for smokers, though they had much higher ranges of values than did non-smokers (Fig. 2).

In newborn males, we found significantly higher levels of testosterone in the children of smokers than for children of non-smokers. Other measured steroids had higher ranges of values in the children of smokers, but the changes were not significant (Fig. 3). For newborn females, we found significantly higher $7 \alpha-\mathrm{OH}-\mathrm{DHEA}$. Other measured hormones showed no significant changes, though again the children of smokers had a higher range of values (Fig. 4). 

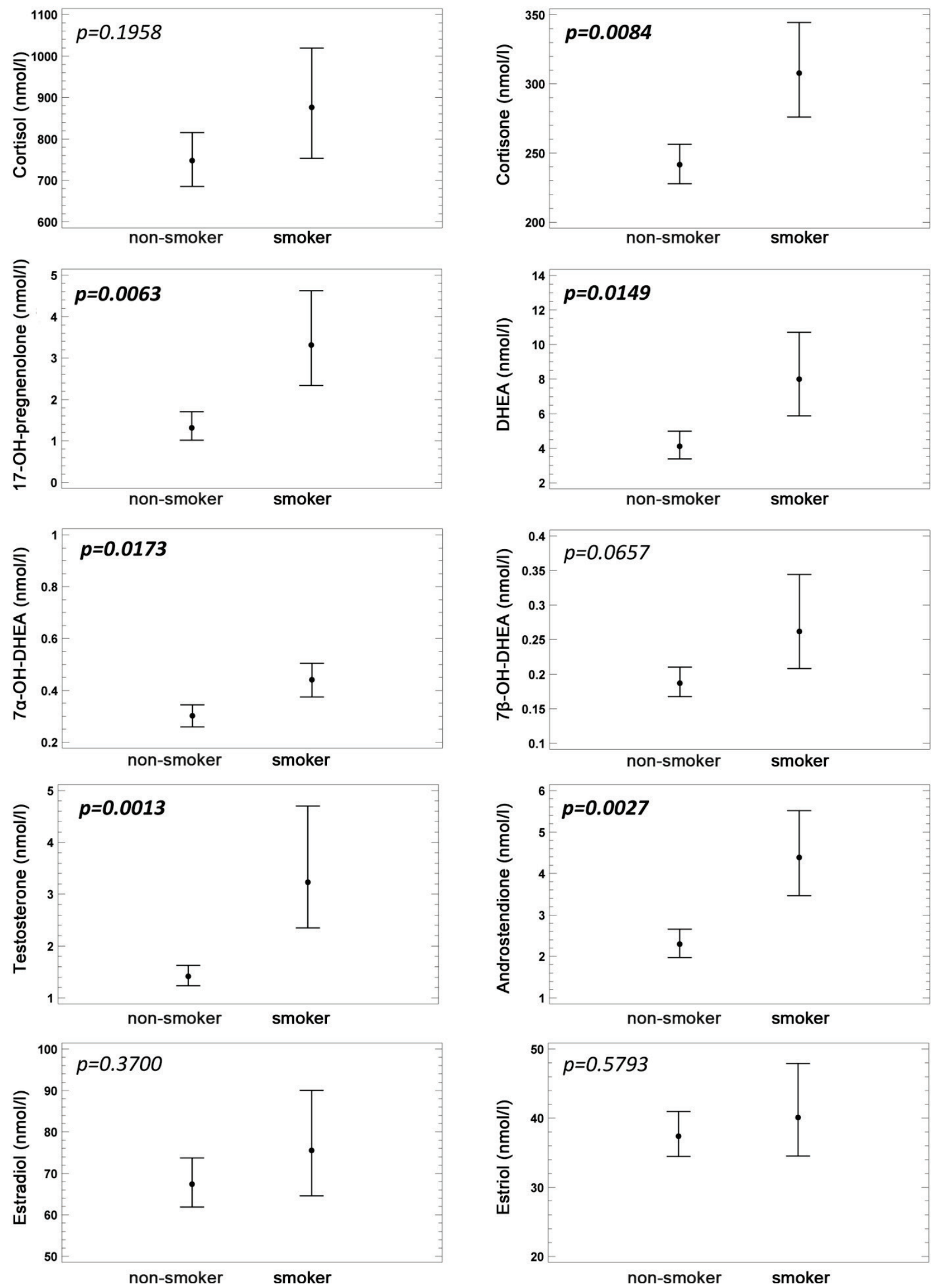

Fig. 1. The comparison of steroid levels in maternal blood between smoking and non-smoking pregnant women in $37^{\text {th }}$ week, who were carrying a male fetus. In women smokers, significantly higher levels of cortisone, DHEA, 7a-OH-DHEA, 17-OH-pregnenolone, testosterone and androstenedione were found. Other tested steroids did not differ between smokers and non-smokers. Error bars represent group means with their $95 \%$ confidence intervals; statistical significance ( $p$-value) is shown in each graph. 

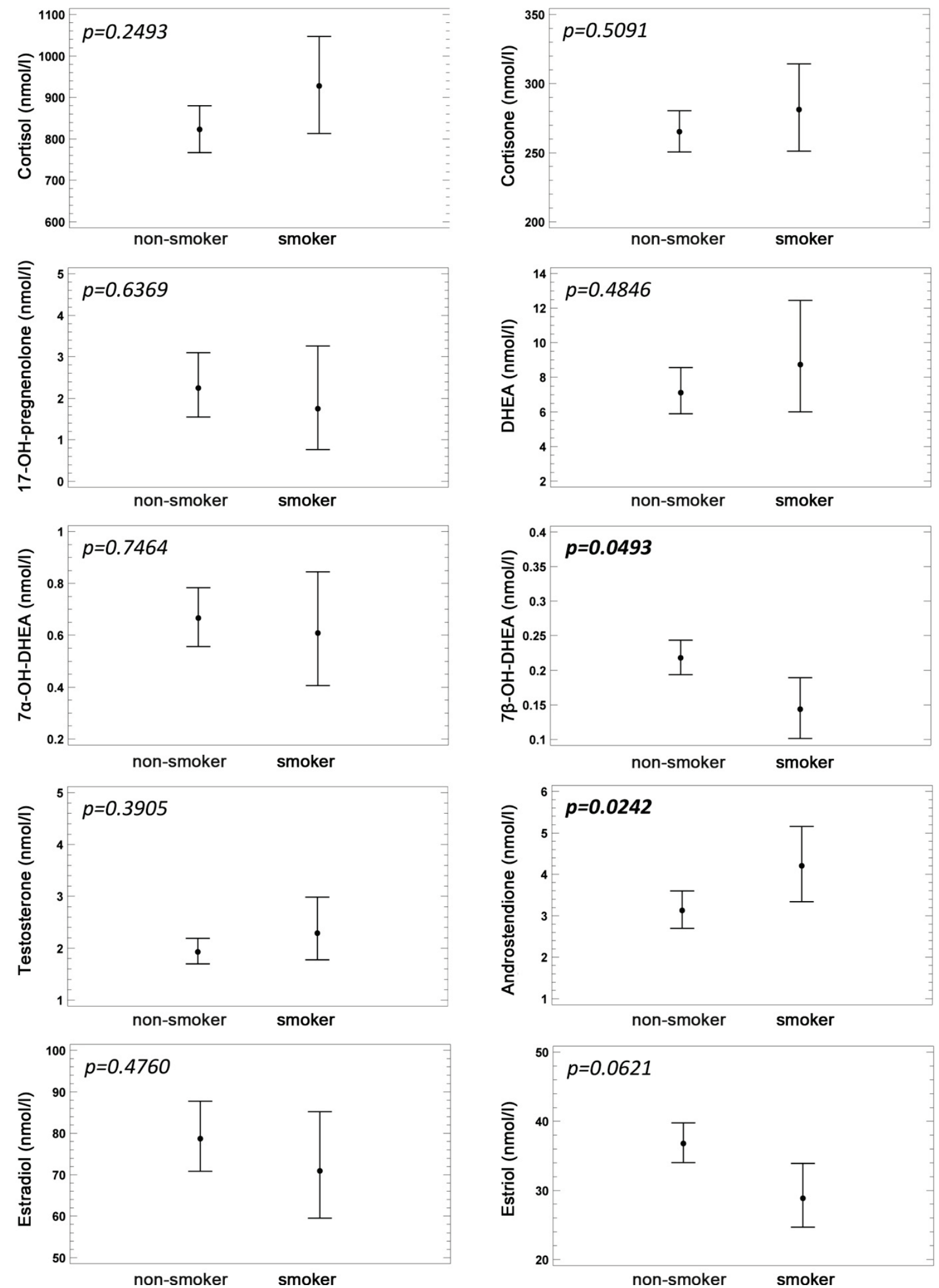

Fig. 2. The comparison of steroid levels in maternal blood between smoking and non-smoking pregnant women in $37^{\text {th }}$ week, who were carrying a female fetus. In women smokers, significantly lower levels of $7 \beta-\mathrm{OH}-\mathrm{DHEA}$ and higher levels of androstenedione were observed. In addition, female smokers had lower estriol, though not statistically significant. Other tested steroids were not different for smokers, but the ranges of values were much greater than for non-smokers. Error bars represent group means with their $95 \%$ confidence intervals; statistical significance ( $p$-value) is shown in each graph. 

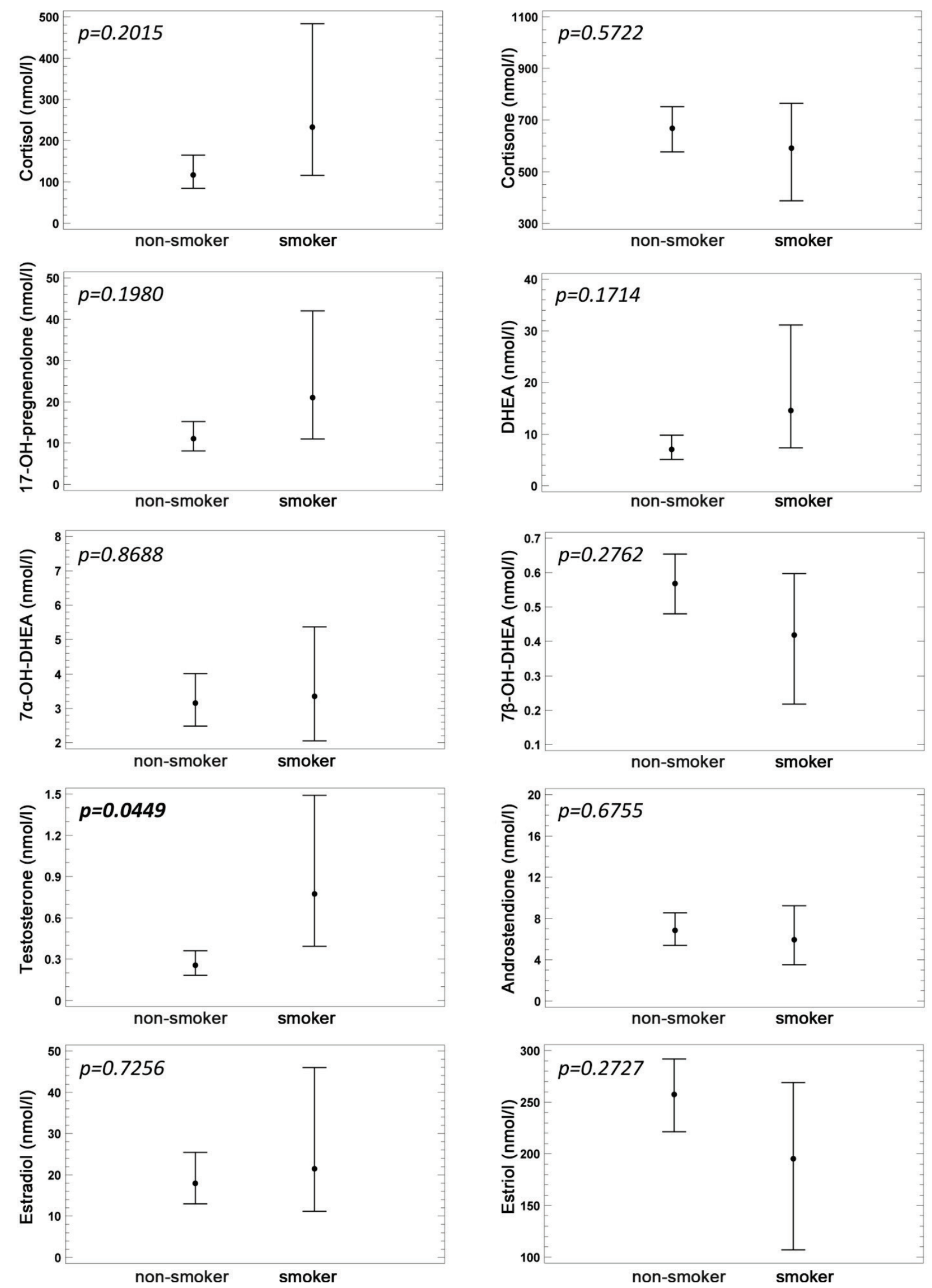

Fig. 3. The comparison of steroid levels in mixture cord blood between male newborn of smoking and non-smoking mothers. In male newborns of smoking mothers, significantly higher levels of testosterone compared to males from non-smokers were found. Other tested steroids had higher range of values in newborns of smokers, but not statistically significant. Error bars represent group means with their $95 \%$ confidence intervals; statistical significance ( $p$-value) is shown in each graph. 

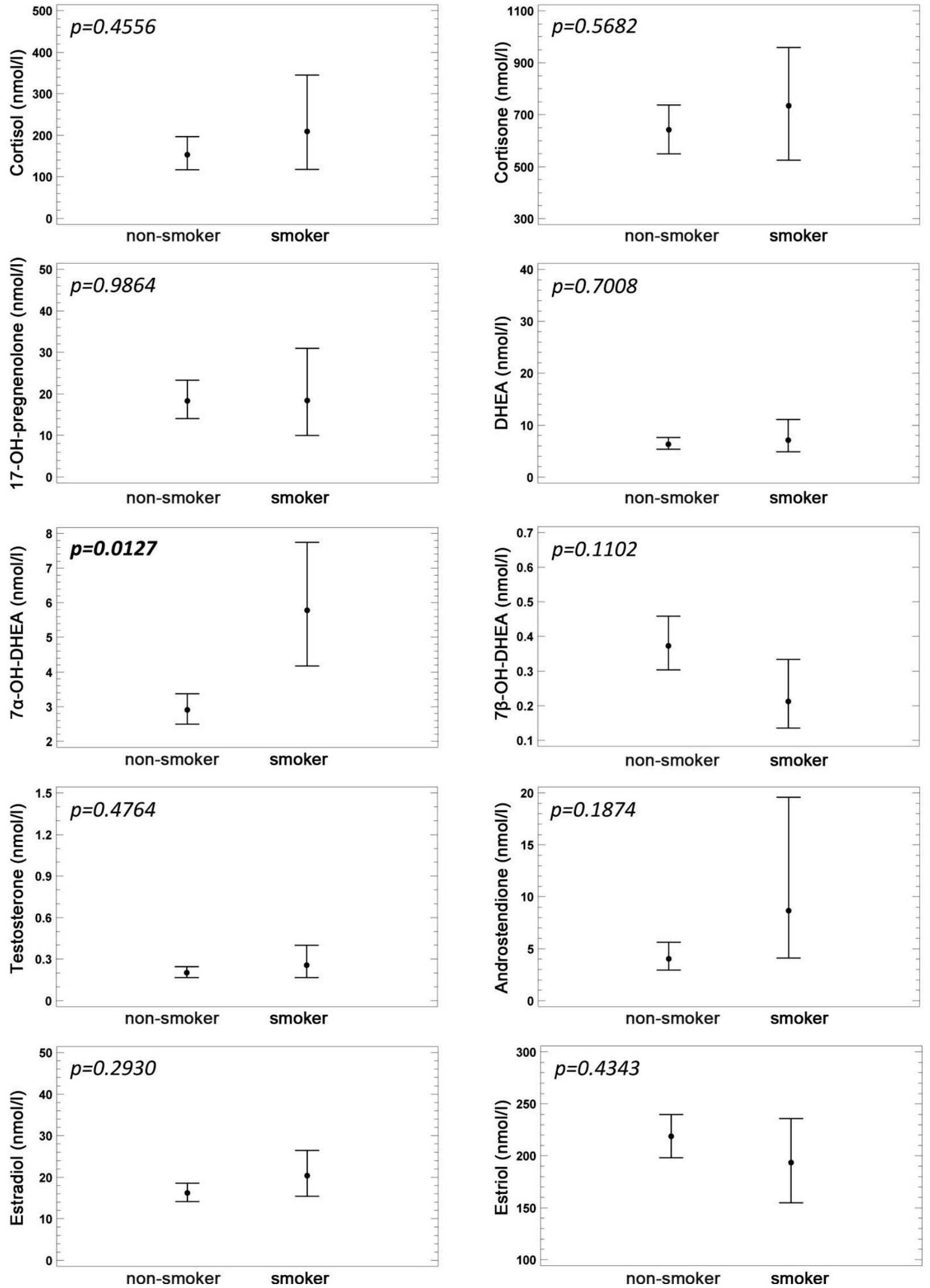

Fig. 4. The comparison of steroid levels in mixture cord blood between female newborn of smoking and non-smoking mothers. In female newborns of smoking mothers, significantly higher levels of 7a-OH-DHEA were observed. Other tested hormones showed non-significant differences, though again newborns of smokers had a higher range of values. Error bars represent group means with their $95 \%$ confidence intervals; statistical significance ( $p$-value) is shown in each graph. 


\section{Discussion}

Smoking of women during pregnancy presents a serious health risk for both the mother and her child, with increased risks of perinatological complications and of developing various disorders later in life. From the point of view of the mother, the increased gain in weight during pregnancy is noteworthy. Our results are in agreement with the study of Rode et al. (2013), which followed changes in weight during pregnancy in 1774 women. They found that women quitting smoking during pregnancy had a higher weight gain than non-smokers, and proposed two possible reasons. First, the absence of nicotine itself, which lowers the rate of stomach emptying, quickens intestinal peristalsis, and increases basal metabolism. Second, women who quit smoking tend to use food that is often high in sugar and fats as a substitute for the positive feelings associated with smoking a cigarette. The average weight gain in women quitting smoking was $2 \mathrm{~kg}$ more than for non-smokers (Rode et al. 2013). We found that women smokers gained an average of $4 \mathrm{~kg}$ more than non-smokers. This could be caused by the fact that most of them reduced the number of cigarettes smoked after finding out they were pregnant, from an average of 21 to 6 cigarettes daily, and thus may have experienced symptoms of abstinence including an increased desire for food.

In addition to the generally well-known effects such as lower newborn birth weights (Ingvarsson et al. 2007), and which we also found in our study, smoking during pregnancy has been found to affect hormonal homeostasis in both the mother and child. When studying the effects of maternal smoking on fetal steroidogenesis and its possible consequences, it is necessary to first take into account the specifics of steroid production and function during pregnancy.

During pregnancy, the production of estrogens (E2 and E1) increases 100-fold, while the production of E3, the main estrogen of pregnancy, increases many times more. Outside of pregnancy, E3 is almost absent in the human organisms. This increase in estrogen concentrations in the maternal blood circulation is dependent on the function of the fetal-placental unit. Dehydroepiandrosterone sulfate (DHEAS) from the fetal adrenal gland is converted to $16 \alpha$-hydroxylase in the fetal liver as a precursor for E3. Shortly after delivery of the child, this activity ceases (Kuijper et al. 2013). In pregnant women, the production of DHEAS increases while serum concentrations are lower than in fertile women outside of pregnancy, likely because of its conversion to estrogens (Tawaga et al. 2004). Androstenedione is an androgen that is a precursor for the production of testosterone and estrogens (E1 and E2). The enzyme 17 $\beta$-hydroxysteroid dehydrogenase changes androstenedione into testosterone, which is then aromatized into estrogens. Placental aromatization is so efficient that any androgens that enter the placenta from the fetus are modified into estrogens. This is crucial for twins of different sexes, to ensure that the female fetus is not influenced by the androgens of her brother, not just for gonadal development but also to prevent male-type behavior (Kuijper et al. 2015). The development of the brain and its sexual differentiation is dependent on steroids produced in the gonads of the fetus. A key part of this is protection of the brain from the excess estrogens that are typical during pregnancy. The developing brain is protected from estrogens by alpha-fetoproteins, which prevent estrogens from entering nerve cells. In males fetuses testosterone produced in the fetal gonads enters the cellular cytoplasm, where it is aromatized into E2 that binds to estrogen receptors of the cell nucleus and is responsible for the development of the male brain (McCarthy 2007). This only happens during the individual's intrauterine period. The specific role of steroids during pregnancy is therefore necessary to consider when evaluating the effects of changes in steroidogenesis induced by smoking, because modifying just one enzyme or steroid levels in just one compartment can lead to changes in all others and affect multiple processes in the developing fetus and its future programming. It is therefore difficult to extrapolate from changes in several steroids to changes overall, but such changes can provide signals that bring attention to such changes and give us information that may help explain those changes described in the children of smokers.

Changes in estrogen due to smoking during pregnancy have been the focus of many studies. Lower levels of E2 have been found in pregnant smokers (Andersen et al. 1984) and in newborns of smoking mothers (Andersen et al. 1984, Varvarigou et al. 2009). In our study, we found only non-significantly lower E3 levels in smokers at the $37^{\text {th }}$ week of pregnancy who were carrying female fetuses.

The influence of maternal smoking on male children has also been the subject of many studies, often in association with defects in adult reproductive function. This has been demonstrated in animal models, though not yet in humans (Ratcliffe et al. 1992). Another study that 
also failed to find an influence on fertility did find, however, a higher ratio of free testosterone to free E2 in the children of smokers. Those data may indicate a shift in the hypothalamic-pituitary-gonadal axis in relation to higher androgenicity (Remlau-Hansen et al. 2008). In line with these results, we found higher levels of testosterone in newborn males of mothers who smoked.

In animal models, higher levels of free testosterone have been found in adult males exposed to the effects of nicotine during their intrauterine life (Smith et al. 2003). There is also data in the literature on testosterone levels in smokers who are pregnant and relationships to smoking in their adult offspring. One interesting finding is the relationship between higher testosterone levels in smoking mothers and smoking in their daughters. Higher testosterone levels in women who smoked during pregnancy correlated with smoking in their daughters, while prenatal cotinine levels were not correlated. Testosterone levels in smoking mothers thus seem to be a risk factor for smoking in their daughters (Kandel et al. 1999). However, these findings were not supported by the study of Stround et al. (2014), which did not find an association with maternal testosterone levels in the third trimester and smoking addition in their adult daughters, but did find a relationship with maternal cortisol in the third trimester. That study also failed to find associations of maternal smoking with either testosterone or cortisol in male offspring. In our study, we found no evidence of changes in testosterone in the newborn girls of mothers who smoked or in the mothers who were carrying female children. However, we did find a higher range of testosterone values, with some levels being very increased. On the other hand, we did find significantly higher levels of androstenedione in women smokers in the $37^{\text {th }}$ week of pregnancy, who carried female fetuses. Many studies using experimental models have found long-term effects of prenatal exposure to nicotine, but only few have tracked differences in light of the sex of the offspring. Even though it has been shown that while prenatal exposure to nicotine induces a range of changes to the structure and function of the child's brain, male offspring suffer even more undesirably side effects to cholinergic, serotonin and $\beta 2$-adrenergic functioning. Exposure to nicotine in utero in male offspring increases the future risk of nicotine addiction, but not in female offspring. Prenatal exposure to nicotine in rodent experimental models increased corticosterone levels by directly affecting the adrenal cortex, which led to significantly higher testosterone levels in the perinatal period (Cross et al. 2016). Our study also found changes in pregnant women smokers who were carrying male children, and in newborn males we found higher testosterone levels. This is in line with the data from experimental models, and indicates that male fetuses are more sensitive to changes induced by smoking.

In smoking mothers with male children we found higher levels of the adrenal steroids cortisone, DHEA, $7 \alpha$-OH-DHEA, and $17 \alpha-\mathrm{OH}-$ pregnenolone compared to non-smokers. In contrast, smoking mothers with female children had significantly lower $73-\mathrm{OH}-$ DHEA of adrenal origin compared to non-smokers, a steroid that is considered to have marked influence on the immune system. Signs of lower E3 levels are also in agreement with the hypothesis that smoking has an undesirable influence on adrenal steroidogenesis, since E3 is produced in the placenta mostly from products of the fetal adrenal glands.

There is data in the literature about changes to the hypothalamic-pituitary-adrenal axis in the children of women who smoked during pregnancy. However, results of studies that followed cortisol are inconsistent, with some finding similar levels and others finding higher. McDonald et al. (2006) measured ACTH and cortisol levels in the cord blood of newborns from planned cesarean sections, and found that in children of smokers ACTH was higher but cortisol was the same. Similar results were found by Sybulski et al. (1977). However, many other studies have found higher cortisol levels in children of smokers (Lieberman et al. 1992, Vavrarigou et al. 2006, Vavrarigou et al. 2009). Vavrarigou et al. (2006) found higher cortisol both in the children of smokers delivered by cesarean section and those delivered vaginally. Cortisol levels in children of smokers born by cesarean section positively correlated with the number of cigarettes smoked by their mothers. In our study, we found higher cortisol levels in the $37^{\text {th }}$ week only in pregnant smokers who carried male fetuses. We found no changes in newborns, but both cortisol and cortisone had much higher ranges of values in both male and female children of smoking mothers compared to children of non-smokers. This could reflect differences in the effects on steroids in individual children of smokers, and may partially explain the inconsistent data in the literature.

Longitudinal studies following changes to the hypothalamic-pituitary-adrenal axis after prenatal exposure to smoking are particularly interesting. Saridjan et al. (2010) measured the diurnal cortisol profiles of 
children from 12 and 20 months, and found that the children of smokers had a positive cortisol reaction after awaking. The study of Scheutze et al. (2008) analyzed the cortisol reaction to stress in seven-month-old children, and found higher levels in those whose mothers smoked during pregnancy. In addition, they found a difference in the reactivity for different sexes, with exposed boys having a higher cortisol reaction than exposed girls. These studies show that prenatal exposure to smoking can influence the programming of the hypothalamic-pituitaryadrenal axis. We did not find sex-related differences in cortisol or differences in the reaction to the stress of birth in newborns.

In general, smoking during pregnancy induces changes in the production of steroids in both the pregnant women and their children. These changes are different for different sexes of fetus, with more marked changes in smokers who are carrying boys as well as in the newborn boys themselves. However, the results of our study are limited by the smaller number of smokers versus controls.

\section{Conflict of Interest}

There is no conflict of interest.

\section{Acknowledgements}

The study was supported by the MEYS CR (OP RDE, Excellent research - ENDO.CZ), by $\mathrm{MH} \mathrm{CZ} \mathrm{-} \mathrm{DRO}$ (Institute of Endocrinology - EÚ, 00023761) and by grant GAUK: Changes in fetal steroidogenesis caused by maternal smoking, no. 542216.

\section{References}

ANDERSEN AN, RØNN B, TJØNNELAND A, DJURSING H, SCHIØLER V: Low maternal but normal fetal prolactin levels in cigarette smoking pregnant women. Acta Obstet Gynecol Scand 63: 237-239, 1984.

CRESSMAN AM, PUPCO A, KIM E, KOREN G, BOZZO P: Smoking cessation therapy during pregnancy. Canad Fam Physician 58: 525-527, 2012.

CROSS J, LINKER E, LESLIE M: Sex-dependent effects of nicotine on the developing brain. $J$ Neurosci Res 95 : 422-436, 2017.

DIVERS WA JR, WILKES MM, BABAKNIA A, YEN SS: Maternal smoking and elevation of catecholamines and metabolites in the amniotic fluid. Am J Obstet Gynecol 141: 625-628, 1981.

DUŠKOVÁ M, ŠIMŮNKOVÁ K, HILL M, VELÍKOVÁ M, KUBÁTOVÁ J, KANCHEVA L, KAZIHNITKOVÁ H, HRUŠKOVIČOVÁ H, POSPÍŠILOVÁ H, RÁCZ B, SALÁTOVÁ M, CIRMANOVÁ V, KRÁLÍKOVÁ E, STÁRKA L, PAŘIZZEK A: Chronic cigarette smoking alters circulating sex hormones and neuroactive steroids in premenopausal women. Physiol Res 61: 97-111, 2012.

DUŠKOVÁ M, HRUŠKOVIČOVÁ H, ŠIMŮNKOVÁ K, STÁRKA L, PAŘÍZEK A: The effects of smoking on steroid metabolism and fetal programming. J Steroid Biochem Mol Biol 139: 138-143, 2014.

INGVARSSON RF, BJARNASON AO, DAGBJARTSSON A, HARDARDOTTIR H, HARALDSSON A, THORKELSSON T: The effects of smoking in pregnancy on factors influencing fetal growth. Acta Paediatr 96: 383-386, 2007.

JANDIKOVA H, DUSKOVA M, SIMUNKOVA K, RACZ B, HILL M, KRALIKOVA E, VONDRA K, STARKA L: The steroid spectrum during and after quitting smoking. Physiol Res 64 (Suppl 2): S211-S218, 2015.

JANDÍKOVÁ H, DUŠKOVÁ M, STÁRKA L: The influence of smoking and cessation on the human reproductive hormonal balance. Physiol Res 66 (Suppl 3): S323-S331, 2017.

KANDEL DB, UDRY JR: Prenatal effects of maternal smoking on daughters' smoking: nicotine or testosterone exposure? Am J Public Health 89: 1377-1383, 1999.

KUIJPER EA, KET JC, CAANEN MR, LAMBALK CB: Reproductive hormone concentrations in pregnancy and neonates: a systematic review. Reprod Biomed Online 27: 33-63, 2013.

KUIJPER EA, TWISK JW, KORSEN T, CAANEN MR, KUSHNIR MM, ROCKWOOD AL, MEIKLE AW, HOMPES PG, WIT JM, LAMBALK CB: Mid-pregnancy, perinatal, and neonatal reproductive endocrinology: a prospective cohort study in twins and singleton control subjects. Fertil Steril 104: 1527-1534, 2015.

KUKLA L, HRUBÁ D, TYRLÍK M: Maternal smoking during pregnancy, behavioral problems and school performances of their school-aged children. Cent Eur J Public Health 16: 71-76, 2008. 
LIEBERMAN E, TORDAY J, BARBIERI R, COHEN A, VAN VUNAKIS H, WEISS ST: Association of intrauterine cigarette smoke exposure with indices of fetal lung maturation. Obstet Gynecol 79: 564-570, 1992.

MCCARTHY M: Estradiol and developing brain. Physiol Rev 88: 91-134, 2008.

MCDONALD SD, WALKER M, PERKINS SL, BEYENE J, MURPHY K, GIBB W, OHLSSON A: The effect of tobacco exposure on the fetal hypothalamic-pituitary-adrenal axis. BJOG 113: 1289-1295, 2006.

MONTGOMERY SM, EKBOM A: Smoking during pregnancy and diabetes mellitus in a British longitudinal birth cohort. BMJ 324: 26-27, 2002.

NECHANSKÁ B, MRAVČÍK V, SOPKO B, VELEBIL P: Pregnant women and mothers using alcohol, tobacco and illegal drugs (in Czech). Ceska Gynekol 77: 457-469, 2012.

RAMLAU-HANSEN CH, THULSTRUP AM, OLSEN J, ERNST E, ANDERSEN CY, BONDE JP: Maternal smoking in pregnancy and reproductive hormones in adult sons. Int J Androl 31: 565-572, 2008.

RATCLIFFE JM, GLADEN BC, WILCOX AJ, HERBST AL: Does early exposure to maternal smoking affect future fertility in adult males? Reprod Toxicol 6: 297-307, 1992.

RODE L, KJÆRGAARD H, DAMM P, OTTESEN B, HEGAARD H: Effect of smoking cessation on gestational and postpartum weight gain and neonatal birth weight. Obstet Gynecol 122: 618-625, 2013.

SARIDJAN NS, HUIZINK AC, KOETSIER JA, JADDOE VW, MACKENBACH JP, HOFMAN A, KIRSCHBAUM C, VERHULST FC, TIEMEIER H: Do social disadvantage and early family adversity affect the diurnal cortisol rhythm in infants? The Generation R Study. Horm Behav 57: 247-254, 2010.

SCHUETZE P, LOPEZ FA, GRANGER DA, EIDEN RD: The association between prenatal exposure to cigarettes and cortisol reactivity and regulation in 7-month-old infants. Dev Psychobiol 50: 819-834, 2008.

SMITH LM, CLOAK CC, POLAND RE, TORDAY J, ROSS MG: Prenatal nicotine increases testosterone levels in the fetus and female offspring. Nicotine Tob Res 5: 369-374, 2003.

SOMM E, SCHWITZGEBEL VM, VAUTHAY DM, CAMM EJ, CHEN CY, GIACOBINO JP, SIZONENKO SV, AUBERT ML, HÜPPI PS: Prenatal nicotine exposure alters early pancreatic islet and adipose tissue development with consequences on the control of body weight and glucose metabolism later in life. Endocrinology 149: 6289-6299, 2008.

SOSVOROVA L, VITKU J, CHLUPACOVA T, MOHAPL M, HAMPL R: Determination of seven selected neuro- and immunomodulatory steroids in human cerebrospinal fluid and plasma using LC-MS/MS. Steroids 98: 1-8, 2015a.

SOSVOROVA L, HILL M, MOHAPL M, VITKU J, HAMPL R: Steroid hormones in prediction of normal pressure hydrocephalus. J Steroid Biochem Mol Biol 152: 124-132, 2015 b.

STROUD LR, PAPANDONATOS GD, SHENASSA E, RODRIGUEZ D, NIAURA R, LEWINN KZ, LIPSITT LP, BUKA SL: Prenatal glucocorticoids and maternal smoking during pregnancy independently program adult nicotine dependence in daughters: a 40-year prospective study. Biol Psychiatry 75: 47-55, 2014.

SYBULSKI S: Umbilical cord plasma cortisol levels in association with pregnancy complications. Obstet Gynecol 50: 308-312, 1977.

TAGAWA N, HIDAKA Y, TAKANO T, SHIMAOKA Y, KOBAYASHI Y, AMINO N: Serum concentrations of androstenediol and androstenediol sulfate, and their relation to cytokine production during and after normal pregnancy. Steroids 69: 675-680, 2004.

TAPP AL, MAYBERY MT, WHITEHOUSE AJ: Evaluating the twin testosterone transfer hypothesis: a review of the empirical evidence. Horm Behav 60: 713-722, 2011.

VARVARIGOU AA, PETSALI M, VASSILAKOS P, BERATIS NG: Increased cortisol concentrations in the cord blood of newborns whose mothers smoked during pregnancy. J Perinat Med 34: 466-470, 2006.

VARVARIGOU AA, LIATSIS SG, VASSILAKOS P, DECAVALAS G, BERATIS NG: Effect of maternal smoking on cord blood estriol, placental lactogen, chorionic gonadotropin, FSH, LH, and cortisol. J Perinat Med 37: 364-369, 2009.

VITKU J, CHLUPACOVA T, SOSVOROVA L, HAMPL R, HILL M, HERACEK J, BICIKOVA M, STARKA L: Development and validation of LC-MS/MS method for quantification of bisphenol A and estrogens in human plasma and seminal fluid. Talanta 140: 62-67, 2015. 
VITKU J, HERACEK J, SOSVOROVA L, HAMPL R, CHLUPACOVA T, HILL M, SOBOTKA V, BICIKOVA M, STARKA L: Associations of bisphenol A and polychlorinated biphenyls with spermatogenesis and steroidogenesis in two biological fluids from men attending an infertility clinic. Environ Int 89-90: 166-173, 2016. 